\title{
Theoretical and experimental analysis on vibrational spectra of formate species adsorbed on $\mathrm{Cu}-\mathrm{Al}_{2} \mathrm{O}_{3}$ catalyst
}

\author{
Hongwei Gao ${ }^{\mathrm{a}, *}$, Tingxia $\mathrm{Yan}^{\mathrm{b}}$, Changbin Zhang ${ }^{\mathrm{c}}$, Hong $\mathrm{He}^{\mathrm{c}}$ \\ ${ }^{a}$ Institute of Watershed Science and Environmental Ecology, Wenzhou Medical College, Zhejiang 325035, China \\ ${ }^{\mathrm{b}}$ State Property Administration Department, Wenzhou Medical College, Zhejiang 325035, China \\ ${ }^{\mathrm{c}}$ Research Center for Eco-Environmental Sciences, Chinese Academy of Sciences, Beijing 100085, China
}

Received 26 December 2007; received in revised form 23 January 2008; accepted 1 February 2008

Available online 13 February 2008

\begin{abstract}
The formation and adsorption of formate species over $\mathrm{Cu}-\mathrm{Al}_{2} \mathrm{O}_{3}$ catalyst at room temperature have been studied by means of in situ diffuse reflectance infrared Fourier transform spectroscopy (DRIFTS) and theory calculations. The geometrical structures and vibration spectra were obtained at the density function theory (DFT) and compared with the corresponding experimental values. Theoretical calculations show that the calculated IR spectra for DFT-PBE1PBE and DFT-MPW1PW91 method are in good agreement with the experimental spectroscopic results. The mechanism of the catalyst deactivation and regeneration was also discussed during the process of the removal of $\mathrm{HCHO}$ on $\mathrm{Cu}-\mathrm{Al}_{2} \mathrm{O}_{3}$ catalyst at room temperature.
\end{abstract}

(C) 2008 Elsevier B.V. All rights reserved.

Keywords: DFT; In situ DRIFTS; Simulated spectra; Formate; $\mathrm{Cu}-\mathrm{Al}_{2} \mathrm{O}_{3}$ catalyst

\section{Introduction}

Formaldehyde (HCHO) is the dominating volatile organic compound (VOC) in the indoor environment [1]. Moreover, HCHO is very bad for health. It can cause the nasal tumors, respiratory tract, eye membranes irritation and skin irritation [2].

Catalytic oxidation is an effective method for removing VOC because VOC can be oxidized into CO over catalyst at much lower temperature than those of thermal oxidation [3-5]. However, catalytic oxidation is still very difficult to eliminate $\mathrm{HCHO}$ at room temperature.

Using adsorbents can effectively remove the $\mathrm{HCHO}$ at room temperature. This method has been studied by many researchers [6-8]. Eriksson et al. [6] have reported the study about the removal of gaseous $\mathrm{HCHO}$ using potassium permanganate, activated carbon and aluminum oxide and so on. Arthur [7] found that HCHO concentration was dropped

\footnotetext{
* Corresponding author. Tel./fax: +86 57786699570.

E-mail address: gaohongw369@hotmail.com (H. Gao).
}

from $1.3-1.8$ to $0.2-0.3 \mathrm{ppm}$ within a few hours but returned to its initial level after 1-5 day through filter beds of potassium permanganate in a mobile house with active airflow. Sekine and Nishimura [8] have reported that copper oxides could react with $\mathrm{HCHO}$ with the high reactivity at room temperature. Recently, Sekine and Nishimura [8] have found that activated carbon particles and manganese oxides not only reduced indoor $\mathrm{HCHO}$ concentration from 0.21 to $0.04 \mathrm{ppm}$ for more than 7 months, but also enhanced the loss of $\mathrm{HCHO}$ gas from building material in apartments.

Although using adsorbents is effective method to remove $\mathrm{HCHO}$ at room temperature, there is still a limited understanding on the formation and configuration of intermediate involved in the reaction. The mechanism of catalyst deactivation and regeneration is also still not clear.

We investigated the adsorption mechanism of formate species on $\mathrm{Cu}-\mathrm{Al}_{2} \mathrm{O}_{3}$ catalyst in our precious paper $[9,10]$. In these papers, we designed and calculated many calculated models: bridging, bidentate and unidentate formate. The results show that the spectrum of bridging formate simulated by DFT evidently best matches the 
experimental counterparts for overwhelming majority of the calculated models.

In this paper, we investigate the formation and adsorption of formate species over $\mathrm{Cu}-\mathrm{Al}_{2} \mathrm{O}_{3}$ catalyst by comparing the calculated spectra at the different methods with experimental one only for bridging formate. The study aims to utilize in situ DRIFTS and stimulant spectrum toward the understanding of the spectrum effect of the calculation method during the process of the removal of $\mathrm{HCHO}$ on $\mathrm{Cu}-\mathrm{Al}_{2} \mathrm{O}_{3}$ catalyst at room temperature.

\section{Experimental}

\subsection{Catalyst preparation}

Utilized $\mathrm{Al}_{2} \mathrm{O}_{3}$ (gamma type) has a total BET surface area of $250 \mathrm{~m}^{2} / \mathrm{g}$ as supporter of $\mathrm{Cu}-\mathrm{Al}_{2} \mathrm{O}_{3}(\mathrm{Cu}$ metal loading: $10 \mathrm{wt} \%$ ) catalyst, which was prepared by an impregnation method with an aqueous solution of copper nitrate, followed by evaporation to dryness in a rotary evaporator under a reduced pressure at $333 \mathrm{~K}$. The wet sample obtained was dried at $393 \mathrm{~K}$ for $12 \mathrm{~h}$, and then calcined in air at $873 \mathrm{~K}$ for $3 \mathrm{~h}$. Before the catalytic tests, the catalysts were sieved into 40-60 meshes.

\subsection{DRIFTS}

DRIFT and in situ DRIFT spectra were recorded in a NEXUS 670-FTIR equipped with a smart collector and a liquid $\mathrm{N}_{2}$ cooled MCT detector. The sample (about $30 \mathrm{mg}$ ) for study was finely grounded and placed in a ceramic crucible. A now of feed gas mixture was controlled by mass now meters. All spectra were measured with a resolution of $4 \mathrm{~cm}^{-1}$ and accumulating 100 scans. A background spectrum was subtracted from each spectrum, respectively.

\section{Theoretical section}

All calculations were performed using the Gaussian98 program [11]. The properties of the calculated model was determined through the application of density functional theory (DFT) using the PBE1PBE [12], PBEPBE [13], LSDA [14], B3LYP [15], MPW1PW91 [16], HCTH [17], HF [18] function and LANL2DZ [19] basis set.

PBE1PBE is the generalized-gradient-approximation exchange-correlation functional of Perdew, Burke and Ernzerhof. PBEPBE is the 1996 functional of Perdew, Burke and Ernzerhof. LSDA (Local Spin Density Approximation) is the synonym SVWN, which requests the Slater exchange and the VWN correlation function. B3LYP uses the non-local correlation provided by the LYP expression, and VWN functional III for local correlation (not functional V). MPW1PW91 uses modified Perdew-Wang exchange and Perdew-Wang 91 correlation. HCTH is the Handy's family functional including gradient-corrected correlation.
The LANL2DZ effective core potential basis set was used for all of the calculations. The LANL2DZ basis replaces the $1 \mathrm{~s}$ through $2 \mathrm{p}$ electrons of the heavy atoms with a potential field for a considerable computational savings. A double- $\zeta$ quality dunning basis was used for the light atoms and the remaining heavy atom electrons. Stability calculations confirmed the ground-state configuration of all the wave functions.

\section{Results and discussion}

\subsection{Experimental spectra}

Fig. 1 shows the in situ DRIFT spectra of $\mathrm{Cu}-\mathrm{Al}_{2} \mathrm{O}_{3}$ catalyst in a flow of $\mathrm{N}_{2}$ at various temperatures (303$553 \mathrm{~K}$ ) after $\mathrm{HCHO}+\mathrm{O}_{2}$ adsorption for $600 \mathrm{~min}$ on the $\mathrm{Cu}-\mathrm{Al}_{2} \mathrm{O}_{3}$. Exposure of this catalyst to the fed gas resulted in the appearance of eight peaks $(2897,2856,2807,2704$, 1597, 1392, 1379 and $1352 \mathrm{~cm}^{-1}$ ). According to previous studies, two strong bands at 1597 and $1352 \mathrm{~cm}^{-1}$ were ascribed to $v_{\mathrm{as}}(\mathrm{COO})$ and $v_{\mathrm{s}}(\mathrm{COO})$ [20-23], the small and shoulder bands at 2897, 2856, 2807 and $2704 \mathrm{~cm}^{-1}$ were assigned to $v(\mathrm{C}-\mathrm{H})$ [21-23], and the peaks at 1392 and $1379 \mathrm{~cm}$ were assigned to $\delta(\mathrm{C}-\mathrm{H})$ [21-23]. No peak of the adsorbed $\mathrm{HCHO}$ could be observed, even at room temperature. The findings showed that a large amount of $\mathrm{HCOOH}$ was formed over $\mathrm{Cu} / \mathrm{Al}_{2} \mathrm{O}_{3}$ surface.

\subsection{Mechanism for the formation of absorbed formate species over $\mathrm{Cu}-\mathrm{Al}_{2} \mathrm{O}_{3}$ catalyst}

On the basis of our previous results, we propose Scheme 1 for the process of the $\mathrm{HCHO}$ elimination over $\mathrm{Cu}-\mathrm{Al}_{2} \mathrm{O}_{3}$.

When the catalyst was exposed to $\mathrm{HCHO}+\mathrm{O}_{2}$ mixture for $600 \mathrm{~min}$, the deactivated $\mathrm{Cu}-\mathrm{Al}_{2} \mathrm{O}_{3}$ catalyst was heated to $773 \mathrm{~K}$ in a flow of $40 \mathrm{~cm}^{3} / \mathrm{min}$ helium. HCHO firstly adsorbed on $\mathrm{Cu}-\mathrm{Al}_{2} \mathrm{O}_{3}$ catalyst surface, and then was oxidized into $\mathrm{HCOOH}$ at room temperature. The results of the in situ DRIFTS, density functional theory calculations and temperature programmed desorption (TPD) showed that $\mathrm{HCHO}$ was completely oxidized into $\mathrm{HCOOH}$ over $\mathrm{Cu}-\mathrm{Al}_{2} \mathrm{O}_{3}$ at room temperature. With increasing the temperature in a flow of helium, $\mathrm{HCOOH}$ was completely decomposed into $\mathrm{CO}_{2}$ over the catalyst surface, and the deactivated $\mathrm{Cu}-\mathrm{Al}_{2} \mathrm{O}_{3}$ is regenerated at the same time. In addition, although $\mathrm{Cu}$ had no obvious influence on the adsorption of $\mathrm{HCHO}$ on $\mathrm{Al}_{2} \mathrm{O}_{3}, \mathrm{Cu}$ dramatically lowered the decomposition temperature of $\mathrm{HCOOH}$ into $\mathrm{CO}_{2}$. It was shown that $\mathrm{Cu}-\mathrm{Al}_{2} \mathrm{O}_{3}$ catalyst had a good ability for the removal of $\mathrm{HCHO}$, and appeared to be promising for its application in destroying $\mathrm{HCHO}$ at room temperature.

\subsection{Optimized structure}

The chemical and optimized structures of the calculation model are plotted in Fig. 2. A comparison of the calculated 


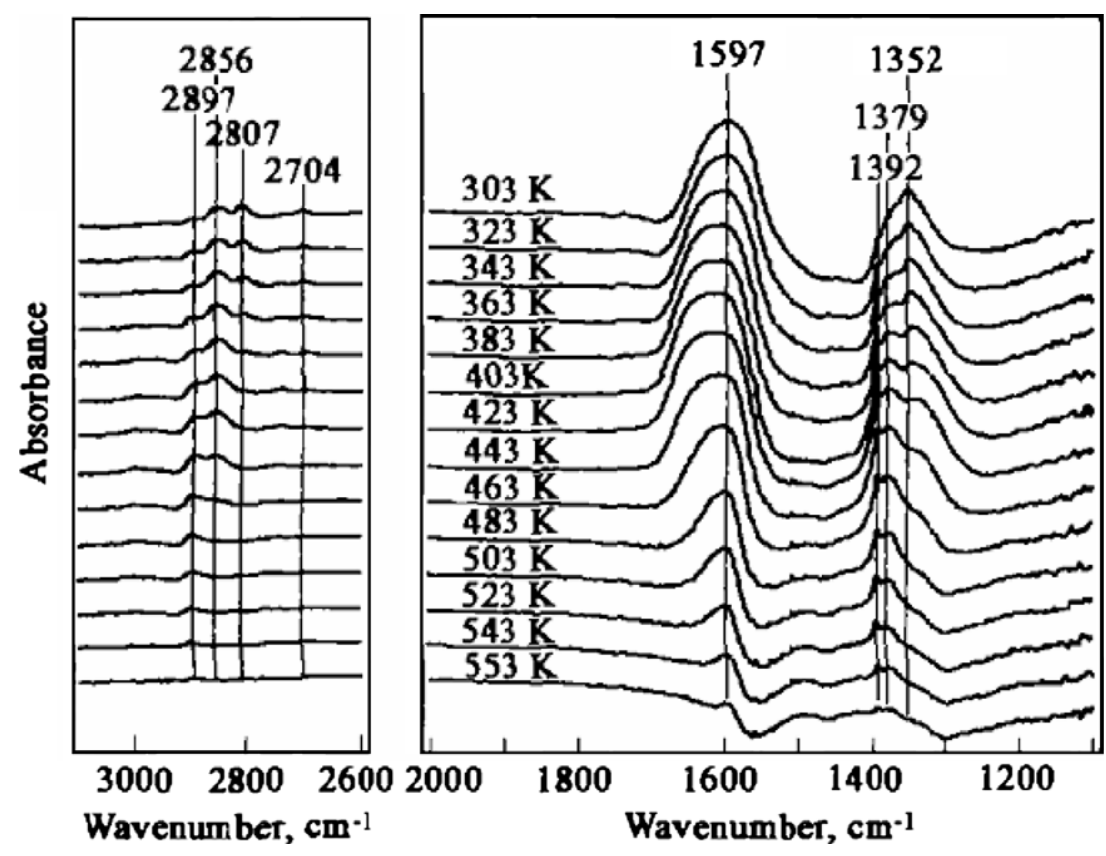

Fig. 1. In situ DRIFT spectra of $\mathrm{Cu}-\mathrm{Al}_{2} \mathrm{O}_{3}$ catalyst in a flow of $\mathrm{N}_{2}$ mixture at various temperatures $(303-553 \mathrm{~K})$ after $\mathrm{HCHO}+\mathrm{O}_{2}$ adsorption for 600 min on the $\mathrm{Cu}-\mathrm{Al}_{2} \mathrm{O}_{3}$ catalyst.

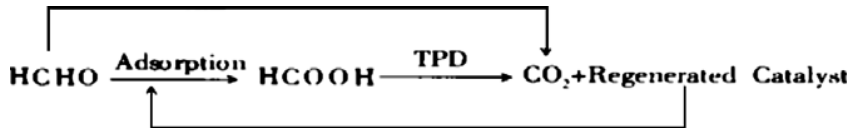

Scheme 1. The process of the $\mathrm{HCHO}$ elimination over $\mathrm{Cu}-\mathrm{Al}_{2} \mathrm{O}_{3}$. a<smiles>O[Al]1OC=CO1</smiles>

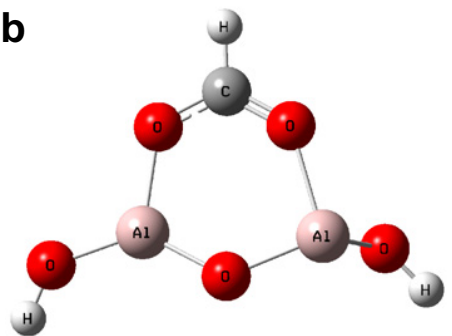

Fig. 2. Formate species adsorption on $\mathrm{Cu}-\mathrm{Al}_{2} \mathrm{O}_{3}$ catalyst: (a) chemical structure of calculation model; (b) optimized structure of calculation model.

bond lengths of $\mathrm{CH}, \mathrm{CO}, \mathrm{AlO}, \mathrm{OH}$ and bond angle of $\mathrm{HCO}$ and $\mathrm{OCO}$ in the calculation model by different methods are presented in Table 1.

Table 1

Experimental and calculated bond length $(\AA)$, angle (deg) of the calculated model for formate species adsorbed on $\mathrm{Cu}-\mathrm{Al}_{2} \mathrm{O}_{3}$ catalyst

\begin{tabular}{lllllll}
\hline Method & $\mathrm{C}-\mathrm{H}(\AA)$ & $\mathrm{C}=\mathrm{O}(\AA)$ & $\mathrm{Al}-\mathrm{O}(\AA)$ & $\mathrm{O}-\mathrm{H}(\AA)$ & $\mathrm{HCO}$ & $\mathrm{OCO}$ \\
\hline PBE1PBE & 1.09207 & 1.31568 & 1.82657 & 0.95876 & 119.53 & 125.56 \\
PBEPBE & 1.10134 & 1.33413 & 1.84577 & 0.97168 & 119.48 & 125.94 \\
LSDA & 1.10124 & 1.32078 & 1.83048 & 0.96757 & 119.54 & 124.91 \\
B3LYP & 1.09304 & 1.32320 & 1.82874 & 0.96175 & 119.70 & 125.37 \\
MPW1PW91 & 1.09050 & 1.31552 & 1.82482 & 0.95776 & 119.56 & 125.51 \\
HCTH & 1.09531 & 1.32519 & 1.83692 & 0.96222 & 119.57 & 125.91 \\
HF & 1.07534 & 1.30091 & 1.80149 & 0.93925 & 119.90 & 124.37 \\
Experiment & 1.09539 & 1.2572 & 1.8270 & 0.9318 & 119.29 & \\
\hline
\end{tabular}

From experimental values of the literature [24-27], $\mathrm{C}-\mathrm{H}$ single bond length is $1.09539 \AA, \mathrm{O}=\mathrm{C}$ double bond length is $1.2572 \AA, \mathrm{Al}-\mathrm{O}$ single bond length is $1.8270 \AA$ and $\mathrm{O}-\mathrm{H}$ bond length is $0.9318 \AA$ for the calculation model. Taking account of the effect of conjugation, our calculated values of the calculation model is in reasonable agreement with the above-mentioned experimental data. The HF/LANL2DZ bond lengths are slightly shorter, while the PBEPBE/LANL2DZ and LSDA/LANL2DZ bond lengths are slightly exaggerated electron correlation effect while the HF theory neglecting this effect. Compared with the experimental values, the PBE1PBE/LANL2DZ and MPW1PW91/LANL2DZ bond lengths are the best.

\subsection{Comparison of simulated and experimental spectra}

The optimized geometries were taken as the basis for the calculation of IR frequencies by a normal coordinate analysis. Simulation spectra of $\mathrm{Cu}-\mathrm{Al}_{2} \mathrm{O}_{3}$ are depicted in Figs. 3 and 4. Calculated vibration frequencies (in $\mathrm{cm}^{-1}$ ) and IR intensity (in $\mathrm{km} / \mathrm{mol}$ ) and corresponding frequencies in the experimental gas-phase spectra are listed in Table 2.

The calculated antisymmetric stretching vibration modes of the adsorbed formate species on $\mathrm{Cu}-\mathrm{Al}_{2} \mathrm{O}_{3}$ catalyst for the calculation model at PBE1PBE, PBEPBE, LSDA, B3LYP, MPW1PW91, HCTH and HF method are $1607,1493,1524,1562,1605,1531$ and $1727 \mathrm{~cm}^{-1}$, respectively (Figs. 3 and 4). In comparison with the same experimental frequency of $1597 \mathrm{~cm}^{-1}$, the error is on average about $10 \mathrm{~cm}^{-1}$ for PBE1PBE method, $-104 \mathrm{~cm}^{-1}$ for PBEPBE method, $-73 \mathrm{~cm}^{-1}$ for LSDA method, $-35 \mathrm{~cm}^{-1}$ for B3LYP method, $8 \mathrm{~cm}^{-1}$ for MPW1PW91 

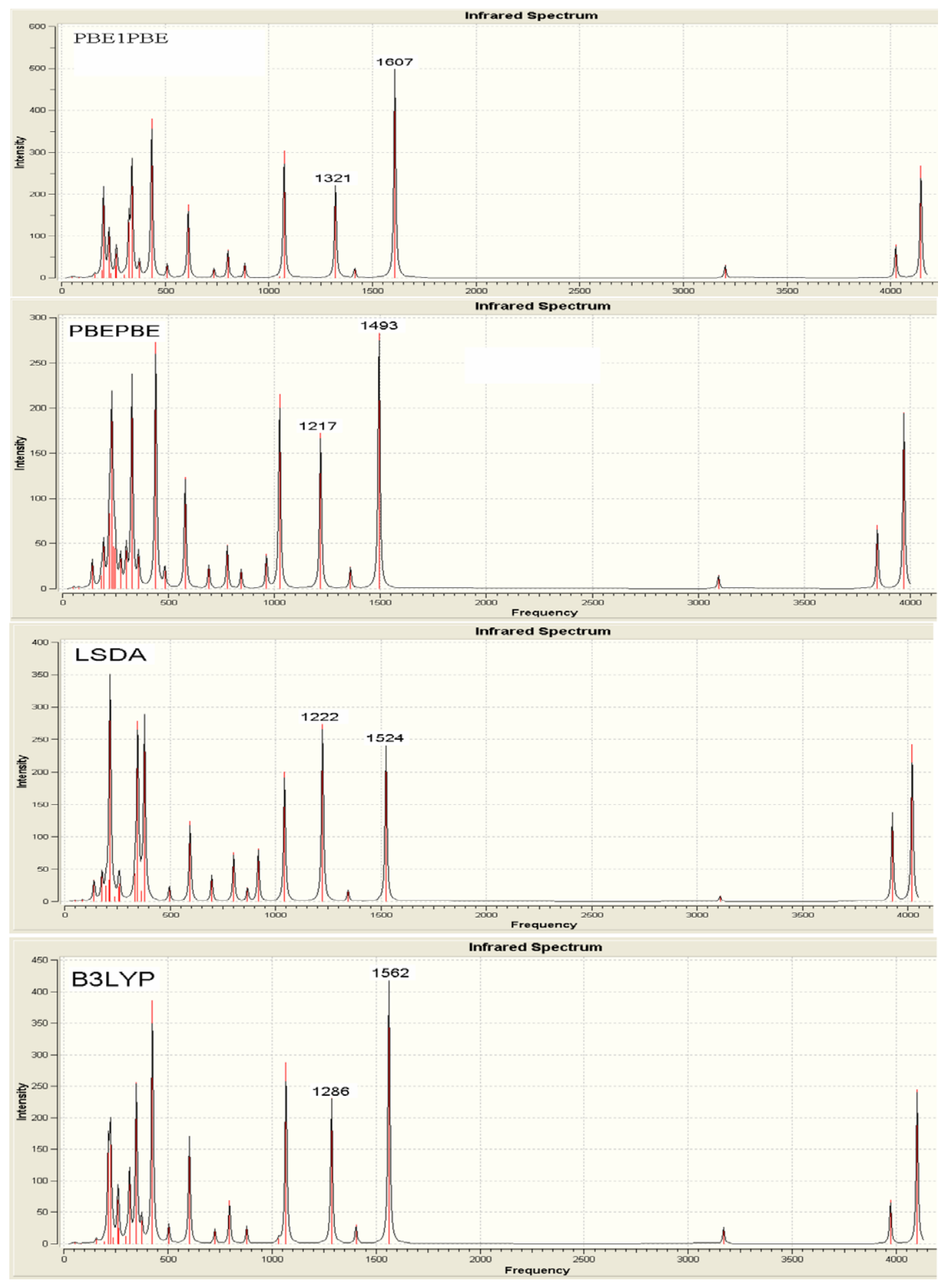

Fig. 3. Calculated vibration IR spectra for the calculation model at PBE1PBE, PBEPBE, LSDA and B3LYP method.

method, $-66 \mathrm{~cm}^{-1}$ for HCTH method and $130 \mathrm{~cm}^{-1}$ for HF method. For the same experimental frequency of $1597 \mathrm{~cm}^{-1}$, overestimation of experimental frequency values is about $0.62 \%$ for PBE1PBE method, $0.5 \%$ for MPW1PW91 method, $8.14 \%$ for HF method; underestimation of experimental frequency values is about $6.51 \%$ for PBEPBE method, $4.57 \%$ for LSDA method, $2.19 \%$ for B3LYP method, $4.13 \%$ for HCTH method. The calcu- lated frequencies of PBE1PBE method for the calculation model at $1607 \mathrm{~cm}^{-1}$ with $510 \mathrm{~km} / \mathrm{mol}$ intensity is relatively good matches of the most intense bands at $1597 \mathrm{~cm}^{-1}$ in the experimental spectrum (Fig. 1). The calculated frequencies of MPW1PW91 method for the calculation model at $1605 \mathrm{~cm}^{-1}$ with $508 \mathrm{~km} / \mathrm{mol}$ intensity is also in good agreement with the experimental value of $1597 \mathrm{~cm}^{-1}$ (Fig. 1). 


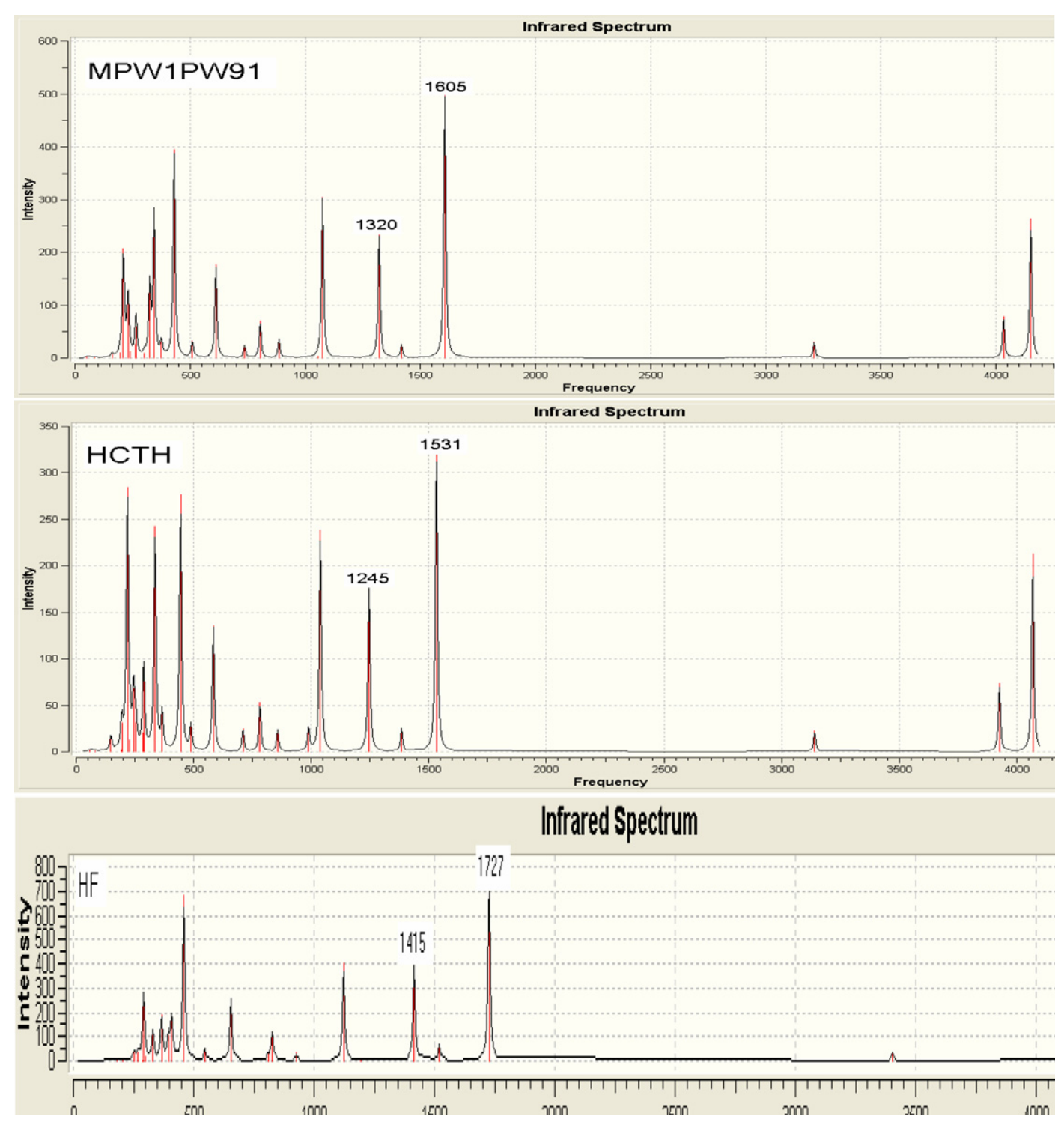

Fig. 4. Calculated vibration IR spectra for the calculation model at MPW1PW91, HCTH and HF method.

The calculated symmetric stretching vibration modes of the adsorbed formate species on $\mathrm{Cu}-\mathrm{Al}_{2} \mathrm{O}_{3}$ catalyst for the calculation model at PBE1PBE, PBEPBE, LSDA, B3LYP, MPW1PW91, HCTH and HF method are 1321, 1217, 1222, 1286, 1320, 1245 and $1415 \mathrm{~cm}^{-1}$, respectively (Figs. 3 and 4). In comparison with the same experimental frequency of $1352 \mathrm{~cm}^{-1}$, the error is on average about $-31 \mathrm{~cm}^{-1}$ for PBE1PBE method, $-135 \mathrm{~cm}^{-1}$ for PBEPBE method, $-130 \mathrm{~cm}^{-1}$ for LSDA method, $-66 \mathrm{~cm}^{-1}$ for B3LYP method, $-32 \mathrm{~cm}^{-1}$ for MPW1PW91 method and $63 \mathrm{~cm}^{-1}$ for HF method. For the same experimental frequency of $1352 \mathrm{~cm}^{-1}$, underestimation of experimental frequency values is about $2.29 \%$ for PBE1PBE method, 9.98\% for PBEPBE method, $9.61 \%$ for LSDA method, $4.88 \%$ for B3LYP method and $2.36 \%$ for MPW1PW91 method; Overestimation of experimental frequency values is about $4.65 \%$ for $\mathrm{HF}$ method. The calculated frequencies of PBE1PBE method for the calculation model at $1321 \mathrm{~cm}^{-1}$ with $237 \mathrm{~km} / \mathrm{mol}$ intensity is relatively good matches of the peak at $1352 \mathrm{~cm}^{-1}$ in the experimental spectrum (Fig. 1). The calculated frequencies of MPW1PW91 method for the calculation model at $1320 \mathrm{~cm}^{-1}$ with $240 \mathrm{~km} / \mathrm{mol}$ intensity is also relatively good matches of the peak at $1352 \mathrm{~cm}^{-1}$ in the experimental spectrum (Fig. 1).

The spectra of the calculation model simulated by DFT-PBE1PBE and DFT-MPW1PW91 evidently best match the experimental counterparts for overwhelming majority of the calculation method considered in the present study.

\section{Conclusion}

DFT and HF calculations on the vibrational frequencies of the adsorbed formate species on $\mathrm{Cu}-\mathrm{Al}_{2} \mathrm{O}_{3}$ catalyst have been carried out. On the basis of the comparison between calculated and experimental results, assignments of fundamental vibrational modes are exam- 
Table 2

Calculated vibration frequencies (in $\mathrm{cm}^{-1}$ ) and IR intensity (in $\mathrm{km} / \mathrm{mol}$ ) for the calculated model at PBE1PBE, PBEPBE, LSDA, B3LYP, MPW1PW91, HCTH and HF method and corresponding frequencies in the experimental gas-phase spectra

\begin{tabular}{llll}
\hline Method & $\begin{array}{l}\text { Frequency } \\
\left(\mathrm{cm}^{-1}\right)\end{array}$ & $\begin{array}{l}\text { Intensity } \\
(\mathrm{km} / \mathrm{mol})\end{array}$ & $\begin{array}{l}\text { Vibration } \\
\text { mode }\end{array}$ \\
\hline PBE1PBE & 1607 & 510 & $v_{\mathrm{as}}(\mathrm{COO})$ \\
& 1321 & 237 & $v_{\mathrm{s}}(\mathrm{COO})$ \\
PBEPBE & 1493 & 296 & $v_{\mathrm{as}}(\mathrm{COO})$ \\
& 1217 & 174 & $v_{\mathrm{s}}(\mathrm{COO})$ \\
LSDA & 1524 & 247 & $v_{\mathrm{as}}(\mathrm{COO})$ \\
& 1222 & 282 & $v_{\mathrm{s}}(\mathrm{COO})$ \\
B3LYP & 1562 & 433 & $v_{\mathrm{as}}(\mathrm{COO})$ \\
& 1286 & 233 & $v_{\mathrm{s}}(\mathrm{COO})$ \\
MPW1PW91 & 1605 & 508 & $v_{\mathrm{as}}(\mathrm{COO})$ \\
& 1320 & 240 & $v_{\mathrm{s}}(\mathrm{COO})$ \\
HCTH & 1531 & 335 & $v_{\mathrm{as}}(\mathrm{COO})$ \\
& 1245 & 182 & $v_{\mathrm{s}}(\mathrm{COO})$ \\
HF & 1727 & 774 & $v_{\mathrm{as}}(\mathrm{COO})$ \\
& 1415 & 396 & $v_{\mathrm{s}}(\mathrm{COO})$ \\
Experiment $\left(\mathrm{cm}^{-1}\right)$ & 1597 & & $v_{\mathrm{as}}(\mathrm{COO})$ \\
& 1352 & & $v_{\mathrm{s}}(\mathrm{COO})$ \\
\hline
\end{tabular}

ined. It is found that the calculated antisymmetric and symmetric stretching vibration modes of the adsorbed acetate species on $\mathrm{Cu}-\mathrm{Al}_{2} \mathrm{O}_{3}$ catalyst at DFT-PBE1PBE and DFT-MPW1PW91 method are in good agreement with experimental data.

The accuracy of DFT calculation is desirable for resolving disputes in vibrational assignments and provides valuable insight for understanding the observed spectral features. Therefore, it is a promising approach for identifying an unknown compound by comparing its vibrational spectrum with calculates results of a few candidates and the DFT-PBE1PBE and DFT-MPW1PW91 calculated results could serve as a guide for a further experimental search for the missing fundamentals of the target molecule.

\section{Acknowledgement}

This work was financially supported by the College Science Fund for Start-up Program of Wenzhou Medical College.

\section{References}

[1] C. Yu, D. Crump, J. Building Environ. 33 (1998) 357.

[2] J.J. Collins, R. Ness, R.W. Tvl, J. Toxicol. Pharmacol. 34 (2001) 17.

[3] J.J. Spivey, J. Ind. Eng. Chem. Res. 26 (1987) 2165.

[4] S. Stiré, S. Minicò, C. Crisafulli, Appl. Catal. B 40 (2003) 43.

[5] S. Stiré, S. Minicò, C. Crisafulli, J. Catal. Commun. 2 (2001) 229.

[6] B. Eriksson, L. Johnanssin, I. Svedung, Filtration of Formaldehyde Contaminated Indoor Air, Copenhagen, 1980.

[7] D. Arthur, A Report to the HCHO Institute by Arthur D, Little Inc., Cambridge, MA, 1981.

[8] Y. Sekine, A. Nishimura, Atmos. Environ. 35 (2001) 2001.

[9] H. Gao, T. Yan, J. Mol. Struct. (THEOCHEM) (2008), doi:10.1016/ j.theochem.2008.02.004.

[10] C.B. Zhang, X.Y. Shi, H.W. Gao, H. He, J. Environ. Sci. 17 (2005) 429.

[11] M.J. Frisch, G.W. Trucks, H.B. Schlegel, G.E. Scuseria, M.A. Robb, J.R. Cheeseman, V.G. Zakrzewski, J.A. Montgomery, R.E. Stratmann, J.C. Burant, S. Dapprich, J.M. Millam, A.D. Daniels, K.N. Kudin, M.C. Strain, O. Frakas, J. Tomasi, V. Barone, M. Cossi, R. Cammi, B. Mennucci, C. Pomelli, C. Adamo, S.Clifford, J. Ochterski, G.A. Petersson, P.Y. Ayala, Q. Cui, K. Morokuma, D.K. Malick, A.D. Rabuck, K. Raghavachari, J.B. Foresman, J. Cioslowski, J.V. Ortiz, A.G. Baboul, B.B. Stefanov, G. Liu, A. Liashenko, P. Piskorz, I. Komaromi, R. Gomperts, R.L. Martin, D.T. Fox, T. Keith, M.A. AI-Laham, C.Y. Peng, A. Nanayakkara, C. Gonzalez, M. Challacombe, P.M.W. Gill, B.G. Johnso, W. Chen, W. Wong, J.L. Andress, M. Head-Gordon, E.S. Replogle, J.A. Pople, Gaussian, Inc., Pittsburgh, PA, 1998.

[12] J.P. Perdew, K. Burke, M. Ernzerhof, Phys. Rev. Lett. 77 (1996) 3865.

[13] J.P. Perdew, K. Burke, M. Ernzerhof, Phys. Rev. Lett. 78 (1997) 1396.

[14] S.H. Vosko, L. Wilk, M. Nusair, Can. J. Phys. 58 (1980) 1200.

[15] A.D. Becke, J. Chem. Phys. 104 (1996) 1040.

[16] C. Adamo, V. Barone, J. Chem. Phys. 108 (1998) 664.

[17] A.D. Boese, N.C. Handy, J. Chem. Phys. 114 (2001) 5497.

[18] R. McWeeny, G. Dierksen, J. Chem. Phys. 49 (1968) 4852.

[19] P.J. Hay, W.R. Wadt, J. Chem. Phys. 82 (1985) 299.

[20] F. Boccuzzi, A. Chiorino, M. Manzoli, J. Power Sources 118 (2003) 304.

[21] G.J. Millar, C.H. Rochester, K.C. Waugh, J. Catal. 155 (1995) 52.

[22] F.Z. Liu, M.M. Yang, W. Zhou, J. Electro. Chem. Commun. 5 (2003) 276.

[23] G.A. Popova, Y.A. Chesalov, T.V. Andrushkevich, J. Mol. Catal. 158 (2000) 345.

[24] A.H. Pakiari, A. Mohajeri, J. Mol. Struct. (THEOCHEM) 583 (2002) 31.

[25] F. Kanamaru, V. Vand, Am. Mineral. 26 (1970) 149.

[26] Z.S. Su, S. Qin, D.Y. Tang, H.Q. Yang, C.W. Hu, J. Mol. Struct. (THEOCHEM) 778 (2006) 41.

[27] A.S. Lipton, M.D. Smith, R.D. Adams, P.D. Ellis, J. Am. Chem. Soc. 124 (2002) 410 